\title{
Article \\ pH-Dependent Degradation of Diclofenac by a Tunnel-Structured Manganese Oxide
}

\author{
Ching-Yao Hu ${ }^{1}\left(\mathbb{D}\right.$, Yu-Jung Liu ${ }^{2}\left(\right.$ and Wen-Hui Kuan ${ }^{3,4, *}$ \\ 1 School of Public Health, Taipei Medical University, Taipei 110, Taiwan; cyhu@tmu.edu.tw \\ 2 Graduate Institute of Environmental Engineering, National Taiwan University, Taipei 106, Taiwan; \\ yujungliu77@gmail.com \\ 3 Department of Safety, Health and Environmental Engineering, Ming Chi University of Technology, \\ New Taipei 24301, Taiwan \\ 4 Chronic Diseases and Health Promotion Research Center, Chang Gung University of Science \\ and Technology, Chiayi 61363, Taiwan \\ * Correspondence: whkuan@mail.mcut.edu.tw; Tel.: +886-2-29089899 (ext. 4653); Fax: +886-29041914
}

Received: 25 June 2020; Accepted: 3 August 2020; Published: 5 August 2020

\begin{abstract}
The mechanism of diclofenac (DIC) degradation by tunnel-structured $\gamma-\mathrm{MnO}_{2}$, with superior oxidative and catalytic abilities, was determined in terms of solution $\mathrm{pH}$. High-performance liquid chromatography with mass spectroscopy (HPLC-MS) was used to identify intermediates and final products of DIC degradation. DIC can be efficiently oxidized by $\gamma-\mathrm{MnO}_{2}$ in an acidic medium, and the removal rate decreased significantly under neutral and alkaline conditions. The developed model can successfully fit DIC degradation kinetics and demonstrates electron transfer control under acidic conditions and precursor complex formation control mechanism under neutral to alkaline conditions, in which the $\mathrm{pH}$ extent for two mechanisms exactly corresponds to the distribution percentage of ionized species of DIC. We also found surface reactive sites $\left(S_{r x n}\right)$, a key parameter in the kinetic model for mechanism determination, to be exactly a function of solution $\mathrm{pH}$ and $\mathrm{MnO}_{2}$ dosage. The main products of oxidation with a highly active hydroxylation pathway on the tunnel-structured Mn-oxide are 5-iminoquinone DIC, hydroxyl-DIC, and 2,6-dichloro-N-o-tolylbenzenamine.
\end{abstract}

Keywords: diclofenac (DIC); $\mathrm{pH}$-dependent degradation mechanism; reactive site; tunnel-structured manganese oxide; $\gamma-\mathrm{MnO}_{2}$

\section{Introduction}

Diclofenac (DIC), one of the most commonly used nonsteroidal anti-inflammatory drugs (NSAIDs) worldwide, is discharged in large amounts from wastewater treatment plants because of its high hydrophilic nature [1] and low biodegradability [2]. Thus, DIC is widely found in the aquatic environment in a range from $\mathrm{ng} / \mathrm{L}$ to $\mu \mathrm{g} / \mathrm{L}$ and is one of the most frequently detected pharmaceutical and personal care products in water [3,4]. No evidence suggests that DIC is harmful to humans; however, it might be toxic to aquatic organisms and harmful to embryos, infants, children, and adults with low immunity and being sensitive to pharmaceuticals [5-8]. Most of the evidence was focused on its adverse effects on the aquatic and terrestrial organisms, which might cause ecological damage [9-11]. Besides, the transformation products of diclofenac might be more toxic than diclofenac [12,13], which needs to be investigated further.

Manganese oxides (Mn-oxides) are effective natural oxidants for organic pollutants including phenols [14], chlorophenol [14-17], aliphatic amines [18] and anilines [16,19] in soils and sediments. In past decades, Mn-oxides have been used to remove antibacterials and compounds with phenolic and fluoroquinolonic moieties [20,21], triazine, aromatic $N$-oxides [22], tetracyclines [23], and estrogenic 
compounds such as the synthetic hormone 17R-ethinylestradiol [24,25] and as an alternative treatment for wastewater or groundwater containing DIC because Mn-oxides are cheap and operated-friendly [26,27]. These compounds may be endocrine disruptors (EDS) and precursors of harmful disinfection byproducts such as haloacetonitriles, haloacetamides, and nitrogenous heterocyclic [28].

In general, Mn-oxides are classified into a layer phase and tunnel structure with edge-sharing and corner-sharing octahedral $\mathrm{MnO}_{6}$, respectively. Studies have commonly used layer-structured birnessite because of its high sorption capacity for target pollutants to remove organic pollutants $[15,20,24]$. Recently, tunnel-structured Mn-oxides have received considerable attention because of their excellent catalytic oxidative capacity for organic pollutant degradation; however, their mechanisms and feasibility remain unclear and must be investigated [29,30]. $\gamma-\mathrm{MnO}_{2}$, a tunnel-structured $\mathrm{Mn}$-oxide, normally contains a combination of pyrolusite $(1 \times 1$ tunnel $)$ and ramsdellite $(1 \times 2$ tunnel $)$ and has been confirmed to be environmentally friendly without apparent cell toxicity [31,32]. To the best of the authors' knowledge, this is the first study investigating the action of $\gamma-\mathrm{MnO}_{2}$ on DIC degradation.

The ionized and acid form of a weak acid such as DIC significantly alters its adsorptive behavior between solution and solid surface, i.e., pollutants adsorption onto oxides from water and analytes separation in high-performance liquid chromatography (HPLC) column. The ionization of a weak acid such as DIC for which forms of the acid exist under different $\mathrm{pH}$ values [33]. The extent of adsorption is, as with anions of a weak acid, strongly dependent on $\mathrm{pH}$ and favored by lower $\mathrm{pH}$ values [34]. In HPLC if the $\mathrm{pH}$ of the sample solution and the eluent is not well-matched with each other and around the $\mathrm{pKa}$ of the organic acid deformed peaks will appear and then mislead the HPLC analysis conclusions $[35,36]$. Therefore, the $\mathrm{pH}$ could influence the mechanism of the antibiotic interaction with the manganese oxide while those issues have not been systematically addressed.

This study investigated the oxidative degradation of DIC on $\gamma-\mathrm{MnO}_{2}$ suspensions by varying the key operating parameter $\mathrm{pH}$, which highly influenced the surface features and redox potential of Mn-oxides [37] and the charge density of the chemical form of DIC [38]. Therefore, degradative mechanisms, intermediates, and final products were investigated in terms of $\mathrm{pH}$ and compared with the performances of other structures of Mn-oxides presented in the literature.

\section{Materials and Methods}

\subsection{Materials}

The sodium diclofenac (CAS 15307-86-5) with a purity of $>98.5 \%$ was purchased from Sigma-A. All other chemicals used in this study were of analytical grade and purchased from Sigma A (St. Louis, MO, USA), J. T. Baker (Phillipsburg, NJ, USA) and Riedel-deHean (Seelze, Germany). Mn-oxide purchased from Tosoh was characterized as tunnel-structured (or molecular sieve) $\gamma-\mathrm{MnO}_{2}$ (JCPDS 14-0644, PANalytical X'Pert Pro MRD diffractometer) with the Brunauer-Emmett-Teller (BET) specific surface area of $45.6 \mathrm{~m}^{2} \mathrm{~g}^{-1}$ (Micrometrics ASAP, USA, 2010) and $\mathrm{pH}_{\mathrm{zpc}}$ of 5.1 (Dispersion Technology, USA, DT-1200).

\subsection{Batch Experiments}

Experiments were conducted as a function of $\mathrm{pH}(4-9)$. For each batch system, various amounts of a $\gamma-\mathrm{MnO}_{2}$ suspension solution were added to $15-\mathrm{mL}$ glass centrifuge tubes. In the solution, $0.005 \mathrm{M}$ $\mathrm{NaH}_{2} \mathrm{PO}_{4}$ and $\mathrm{NaH}_{2} \mathrm{BO}_{3}$ were added as a buffer. Various proportions of $0.1 \mathrm{M} \mathrm{HCl}$ and $\mathrm{NaOH}$ were used to adjust $\mathrm{pH}$ to the designed value within a controlled range $( \pm 0.07)$. After each reaction course, the solution $\mathrm{pH}$ was remeasured to confirm that it remained within the controlled range. For simplification, the $\mathrm{pH}$ value is indicated as the designed value in the following paragraphs. The initial concentration of sodium diclofenac (CAS 15307-86-5) prepared was $100 \mu \mathrm{M}$, which was confirmed to be completely soluble, with a water solubility of $10^{-5.1}-10^{-1.78} \mathrm{M}[39,40]$. The centrifuge tubes were covered with an aluminum foil to prevent light exposure. The suspensions were rotated 
at $25{ }^{\circ} \mathrm{C}$ through end-over-end rotations at $10 \mathrm{rpm}$ for a specific time in kinetic trials and $24 \mathrm{~h}$ in thermodynamic tests. All experiments were conducted in duplicate. Moreover, controls $\left(\mathrm{no}^{\mathrm{MnO}} 2\right.$ powder) were established using a similar preparatory process to account for sorption on glass tubes and other reactions in the solution.

\subsection{Sample Preparation and Analysis}

After reactions, the suspensions were centrifuged (Pico 17, Thermo Scientific, Waltham, MA, USA) at $8000 \mathrm{rpm}$ for $40 \mathrm{~min}$, and then the supernatant was quantified using high-performance liquid chromatography (HPLC, L-7200, Hitachi, Japan) with a diode array (DAD) detector (L-7455, Hitachi) at $270 \mathrm{~nm}$. Chromatographic separation was conducted using an RP-18 column $(150 \mu \mathrm{m} \times 4.6 \mu \mathrm{m}$ and an internal diameter of $5 \mu \mathrm{m}$ ) purchased from Mightysi with an eluent comprising $60 \%$ acetonitrile and $40 \%$ acidified water ( $25 \mathrm{mM}$ phosphoric acid). The flow rate and injection volume were $1 \mathrm{~mL} \mathrm{~min}^{-1}$ and $20 \mu \mathrm{L}$, respectively.

\subsection{Identification of Oxidation Products}

Major oxidation products were identified using HPLC with mass spectrometry (HPLC-MS). The HPLC-MS system comprised an Agilent 1100 Series liquid chromatography system (LC, Agilent, Palo Alto, CA, USA) with a CTC PAL auto-sampler (CTC Analytica, Carrboro, NC, USA) separation module interfaced with an API 4000 triple quadrupole mass spectrometer (Applied Biosystems AB/MDS Sciex, Foster City, CA, USA). The LC column was a Luna Polar RP (150 mm $\times 2.1 \mathrm{~mm}$ internal diameter $)$ column purchased from Phenomenex (Torrance, CA, USA). The flow rate and injection volume were

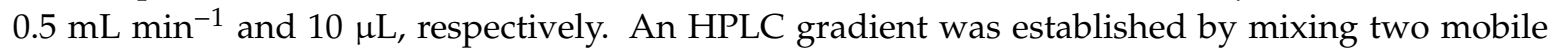
phases: acetonitrile and deionized water, with $10 \mathrm{mM}$ formic acid. Chromatographic separation was achieved with the following gradient: 0 to $1 \mathrm{~min}$ : $0 \%$ acetonitrile; $1-5 \mathrm{~min}$ : linear-gradient to 100\% acetonitrile; 5-10 min: 100\% acetonitrile; 10 to $10.1 \mathrm{~min}$ : 0\% acetonitrile; and $10.1-15 \mathrm{~min}$ : 0\% acetonitrile. Mass spectrometer parameters operated in a positive ion mode were as follows: curtain gas, 20 psi; ion source gas 1, 30 psi; ion source gas 2, 40 psi; source temperature, $500{ }^{\circ} \mathrm{C}$; entrance potential, $10 \mathrm{~V}$; and nebulizer current, $5 \mu \mathrm{A}$, and the interface heater was turned on. Positive ions in the range of $100-500 \mathrm{~m} / \mathrm{z}$ were scanned at a cycle time of $1 \mathrm{~s}$. The data obtained were processed with Analyst 1.4.2 software.

\section{Results and Discussions}

\subsection{DIC Degradation Kinetics on the Tunnel-Structured Mn-Oxide}

Figure 1 presents the kinetic data of DIC degradation on the tunnel-structured Mn-oxide denoted as dot symbols. Interfacial reactions between $\mathrm{DIC}$ and $\gamma-\mathrm{MnO}_{2}$ were highly $\mathrm{pH}$-dependent and initially involved a rapid removal of DIC, followed by gradual slowdown and eventual approach to a plateau. In the acidic medium ( $\mathrm{pH} 4-6$ ), the gradual slowdown period was longer than that in neutral and alkaline conditions ( $\mathrm{pH}$ 7-9) within the tested $\mathrm{pH}$ range. The complicated and multistep reactions between the organic micropollutant interface and Mn-oxides result in limitations of kinetics studies; therefore, only initial reaction rates have been explored in most studies and have been generally characterized with a pseudo-first-order degradation model [27,41]. However, the pseudo-first-order kinetics may not satisfy conditions for the later stage of the interfacial reaction. In general, the interfacial reaction can be initiated by the formation of a precursor complex between the Mn(IV) of oxide surface and target organic pollutants, subsequently followed by electron transfer within the precursor complex, redox product formation (Equations (1)-(5)). Either formation of the precursor complex (Equation (1)) or electron transfer within the precursor complex (Equation (2)) is likely to be the rate-limiting step [42]. The formation of redox products, including the surface $\mathrm{Mn}(\mathrm{III})$ and $\mathrm{Mn}(\mathrm{II})$ (Equation (4)), and further oxidization or combination of organic radicals to form products (Equation (5)), was rapid because of the unstable nature of intermediates. 


$$
\begin{gathered}
\equiv M n^{I V}+D I C \underset{k_{-1}}{\stackrel{k_{1}}{\rightarrow}} \equiv M n^{I V} \cdots D I C \\
\equiv M n^{I V} \cdots D I C \underset{k_{-2}}{\stackrel{k_{2}}{\leftarrow}} \equiv M n^{I I I} \cdots D I C \\
\equiv M n^{I I I} \cdots D I C \underset{k_{-3}}{\stackrel{k_{3}}{\rightarrow}} \equiv M n^{I I I}+D I C \\
\equiv M n^{I I I} \stackrel{\text { fast }}{\rightarrow} \equiv M n^{I I} \\
\text { DIC } \cdot \stackrel{\text { fast }}{\rightarrow} \text { products }
\end{gathered}
$$

An integrated kinetic model [42] was applied to examine the DIC reaction over $\gamma-\mathrm{MnO}_{2}$. The kinetic equation can be expressed as follows:

$$
\frac{d\left[\equiv M n^{I V} \cdots D I C\right]}{d t}=k_{1}\left[\equiv M n^{I V}\right][D I C]-k_{-1}\left[\equiv M n^{I V} \cdots D I C\right]-k_{2}\left[\equiv M n^{I V} \cdots D I C\right]
$$

Total reactive surface sites (S) for DIC degradation can be represented as follows:

$$
S=\left[\equiv M n^{I V}\right]+\left[\equiv M n^{I V} \cdots D I C\right]+\left[\equiv M n^{I I I} \cdots D I C \cdot\right]+\left[\equiv M n^{I I I}\right]+\left[\equiv M n^{I I}\right]
$$

Both $\equiv \mathrm{Mn}^{\mathrm{III}}$-DIC and $\equiv \mathrm{Mn}^{\mathrm{III}}$ are negligible in Equation (7) because of their high instability. The $\equiv \mathrm{Mn}^{\mathrm{II}}$ concentration can be calculated with the concentration difference between parent DIC at initial $\left(\mathrm{C}_{0}\right)$ and specific $(C)$ times on account of two electrons transferred from parent DIC to Mn-oxide [43]. To verify the rate-limited step and degradation mechanism, $k_{1} C>>k_{-1}+k_{2}$ and $k_{-1}+k_{2}>>k_{1} C$, respectively, were assumed for electron transfer control and precursor complex formation control, and the analytical solution of Equation (6) for electron transfer control kinetic model is as follows:

$$
C=\left(C_{0}-S\right)+S e^{-k_{e t} t}
$$

where $k_{e t}$ equals to $k_{2}$ and represents the rate constant of the electron transfer control mechanism.

The analytical solution for the precursor complex formation control model is as follows:

$$
C=\frac{S-C_{0}}{\frac{S}{C_{0}} e^{k_{p f}}\left(S-C_{0}\right) t}-1
$$

where $k_{p f}$ equals to $\frac{k_{1} k_{2}}{k_{-1}+k_{2}}$ and denotes the rate constant of the precursor formation control mechanism. 


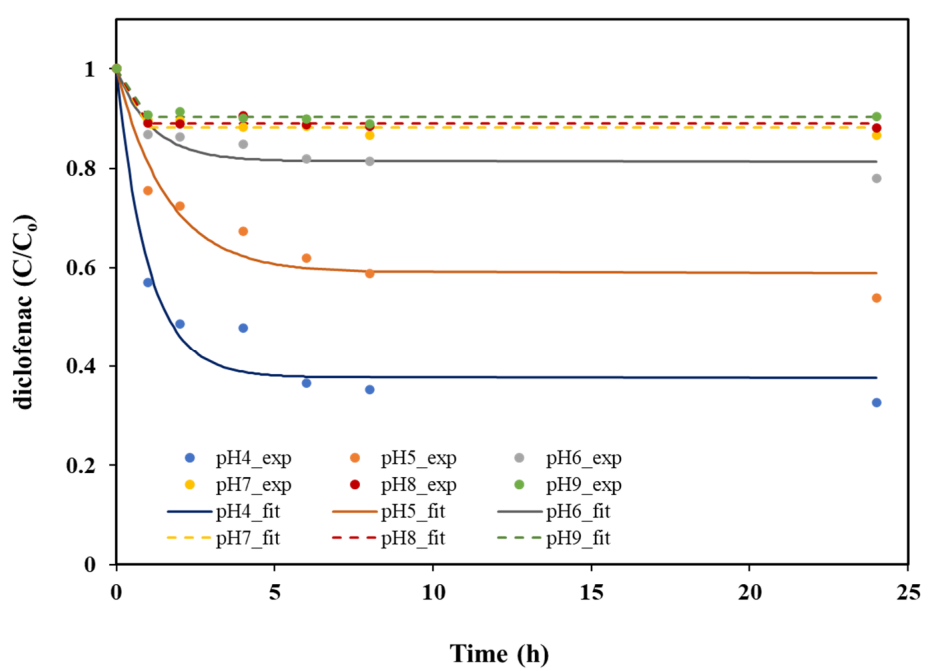

Figure 1. Diclofenac (DIC) oxidation by Mn-oxide. The initial $\gamma-\mathrm{MnO}_{2}$ dosage $\left(\left[\mathrm{MnO}_{2}\right]_{0}\right)$ was $(100 \mathrm{mg} / \mathrm{L})(1150 \mu \mathrm{M})$ and the initial DIC concentration ([DIC $\left.]_{0}\right)$ was $100 \mu \mathrm{M}$. Dotted symbols represent the experimental data, lines indicate the fitting model, solid lines denote the electron-transfer control mechanism model, dash lines indicate the precursor complex-formation control mechanism model.

\subsection{Correlation between $\mathrm{pH}$ and Oxidative Kinetic Constants}

The $\mathrm{pH}$ of the solution shifted the degradation kinetics from electron-transfer control to precursor complex-formation control (Figure 1). The electron-transfer control mechanism model successfully described degradation evolution with time under acidic conditions ( $\mathrm{pH} 4-6)$, whereas under neutral-to-alkaline conditions ( $\mathrm{pH} 7-9$ ), the precursor complex-formation control mechanism was highly fitting to the experimental data (high r-value in Table 1). As Table 1 indicates, the pHs (7-9) with precursor complex-formation control mechanism exactly correspond to the DIC existing as $100 \%$ ionized species. Figure S1 (supplementary materials) displayed the DIC species distribution versus solution $\mathrm{pH}$ based on the calculation of DIC's pKa 4.15 [43].

When $\mathrm{pH}$ was higher than 7 , the ionized species account for $100 \%$ of DIC in solution. Since the formation of precursor complex of DIC with the $\gamma-\mathrm{MnO}_{2}$ surface is coupled with a release of $\mathrm{OH}^{-}$ ions [34], the anionic species of DIC confront with the competition of $\mathrm{OH}^{-}$ions for the surface sites under $\mathrm{pH}$ 7-9. Thus, adsorption was not favored by higher $\mathrm{pH}$ value (7-9) and the precursor complex formation becomes the control mechanism.

Moreover, the rate constant $\left(\mathrm{k}_{\mathrm{et}}\right.$ or $\mathrm{k}_{\mathrm{pf}}$ ) and surface reaction site (S) for DIC degradation decreased when $\mathrm{pH}$ increased (Table 1). The inverse relationship between $\mathrm{k}$ and $\mathrm{pH}$ for DIC could be partially attributed to a decrease in the reduction potential of $\mathrm{MnO}_{2}$ with an increase in $\mathrm{pH}$ (Equation (10)).

$$
M n \mathrm{O}_{2}+4 \mathrm{H}^{+}+2 e^{-} \leftrightarrow \mathrm{Mn}^{2+}+2 \mathrm{H}_{2} \mathrm{O} E_{H}=E_{H}^{0}+0.0296 \log \frac{\left\{\mathrm{MnO}_{2}\right\}\left\{H^{+}\right\}^{4}}{\left\{M n^{2+}\right\}} .
$$

Table 1. Fitting constants (k and S) of the kinetic model under various $\mathrm{pH}$.

\begin{tabular}{cccccc}
\hline $\mathbf{p H}$ & $\mathbf{k}_{\mathbf{e t}} \mathbf{~ o r ~} \mathbf{k}_{\mathbf{p f}}$ & $\mathbf{S}(\boldsymbol{\mu M})$ & $\mathbf{r}$ & Kinetic Model & Ionized Species of DIC $(\%)^{\dagger}$ \\
\hline 4.0 & 0.998 & 62.3 & 0.96 & et * & 41.5 \\
5.0 & 0.623 & 41.1 & 0.94 & et & 87.6 \\
6.0 & 0.887 & 18.6 & 0.91 & et & 98.6 \\
7.0 & 0.590 & 11.8 & 0.93 & pf ${ }^{\#}$ & 100 \\
8.0 & 0.588 & 11.0 & 0.97 & pf & 100 \\
9.0 & 0.541 & 9.7 & 0.96 & pf & 100 \\
\hline
\end{tabular}

* et: electron-transfer-limited mechanism; \# pf: precursor complex-formation-limited mechanism; + calculated by the DIC's pKa 4.15. 
In addition to reducing the potential, solution $\mathrm{pH}$ alters the amounts of surface reactive sites (S, Table 1). Under acidic conditions, a large amount of $S$ was expected because of the relatively strong affinity of anionic DIC ( $\mathrm{pKa}=4.15$ [44]) species on the surface of net positively charged $\mathrm{MnO}_{2}$. Consequently, electron transfer was limited against sufficient active reaction sites for DIC within the tested acidic $\mathrm{pH}(4-6)$. When $\mathrm{pH}$ increased, electrostatic attraction between the net negatively charged surface and anionic DIC species decreased. Furthermore, $\mathrm{OH}^{-}$strongly competed against DIC for surface-bound $\mathrm{Mn}(\mathrm{IV})$. A lower amount of $\mathrm{S}$ at higher $\mathrm{pH}$ represented insufficient active reaction sites for DIC attachment, leading to the removal mechanism to shift to precursor complex-formation control mechanism. In addition, each component was actually derived from the initial dosage of $\mathrm{MnO}_{2}$ (Equation (7)); therefore, surface reaction sites were presumed to be functions of initial dosage of $\mathrm{MnO}_{2}$ and solution $\mathrm{pH}$ :

$$
S=\left[\mathrm{MnO}_{2}\right]\left[\mathrm{H}^{+}\right]^{n} .
$$

To present the $\mathrm{H}^{+}$concentration as $\mathrm{pH}$, the $\log$ form can be written as follows:

$$
\log S=\log \left[\mathrm{MnO}_{2}\right]-n p H .
$$

To investigate the influence of $\mathrm{pH}$ on $\mathrm{S}$ and the kinetic mechanism shift, the $\log \mathrm{S}$ values extracted from Table 1 and the $\log$ value of original $\mathrm{MnO}_{2}$ loading $(\log 1150=3.06)$ were plotted as a function of $\mathrm{pH}$ (Figure 2). The influencing order (n) of $\mathrm{pH}$ was determined as the slope of the straight line of correlation and was equal to 0.24 . The correlation coefficient ( $\mathrm{r}$ ) of 0.95 corroborates the presumption that the amounts of surface reactive sites are the function of solid oxidant loadings and solution $\mathrm{pH}$.

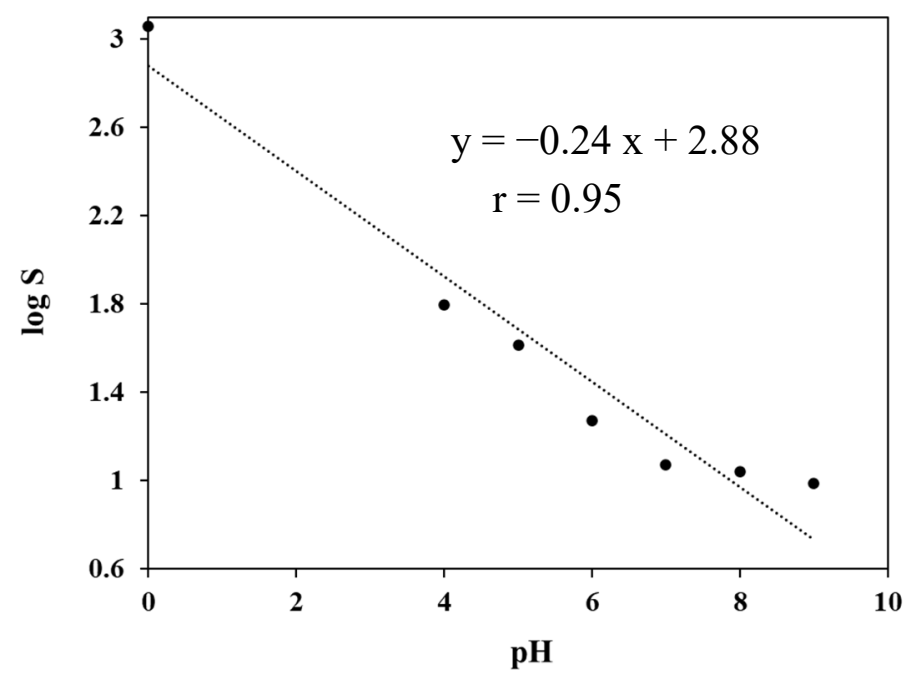

Figure 2. Surface active sites (S) relative to solution $\mathrm{pH}$.

Compared with the Mn-oxide dosage yield (total mole of DIC removal per mole of $\mathrm{MnO}_{2}$ dosage), that for DIC removal by employing $\gamma-\mathrm{MnO}_{2}$ in this study was 0.07 , which falls in relatively higher than $4.49 \times 10^{-4}-0.14$ reported in studies on DIC degradation using other structured Mn-oxides [27,45,46], at $24 \mathrm{~h}$ under similar $\mathrm{pH}$ conditions. Despite varying the DIC concentration and Mn-oxide dosage from $\mu \mathrm{M}$ to $\mathrm{mM}$ in these studies, degradation efficiencies could be compared in a unified manner when the oxide dosage yield was introduced. The remarkable differences in dosage yields indicated that the structure of Mn-oxides substantially influenced their degradative capacity toward DIC, and striking differences were observed for their sorption, oxidative, catalytic, and electrochemical properties [47-49]. The higher oxide dosage yield of $\gamma-\mathrm{MnO}_{2}$ could be ascribed to the higher amounts of more flexible corner-shared $\mathrm{MnO}_{6}$ sites dominated in Mn-oxide bulk, which may facilitate oxidation for target pollutant degradation [49-51]. 


\subsection{Identification of Oxidation Products Using HPLC-MS}

HPLC-MS was used to determine the M/Z ratio of parent DIC, oxidation intermediates (reaction time of $2 \mathrm{~h}$ ), and products (reaction time of $24 \mathrm{~h}$ ), and Figures 3-5, respectively, present their MS chromatograms. Figure 3 a has a peak with a very pronounced tailing and this phenomenon should be due to the $\mathrm{pH}$ mismatch effect mentioned in a previous study [35]. This fact should not affect the identification of the oxidation intermediates and products because the pronounced tail did not appear after reaction (because the concentration of DIC decreased significantly) and most of the compounds did not appear in this region. System peaks were observed in Figure 4 (Figure 4a,b) and Figure S2. This phenomenon reflected some compounds which are strongly absorbed to the stationary phase were generated after reaction [36]. These compounds cannot be identified using this effluent procedure.

Under neutral-to-alkaline conditions, no intermediates were detected at a reaction interval of $2 \mathrm{~h}$, and compared with acidic conditions, fewer oxidative products were obtained at $24 \mathrm{~h}$ according to MS analysis results (Figure S2). Because of the relatively low degradation of DIC under neutral and alkaline conditions, the MS analyses of intermediates and final products were mainly conducted under the acidic condition.

Because of the ionic nature of DIC, two electrospray ionization (ESI) methods, ESI+ and ESI-, were employed to study degradation products, and Table 2 presents the results. Under acidic conditions, three intermediates $\left(\mathrm{I}_{1}, \mathrm{I}_{2}\right.$, and $\left.\mathrm{I}_{3}\right)$ were formed after $2 \mathrm{~h}$ of the reaction, and four final products $\left(\mathrm{F}_{1}, \mathrm{~F}_{2}\right.$, $\mathrm{F}_{3}$, and $\mathrm{F}_{4}$ ) were obtained after a day of the reaction.
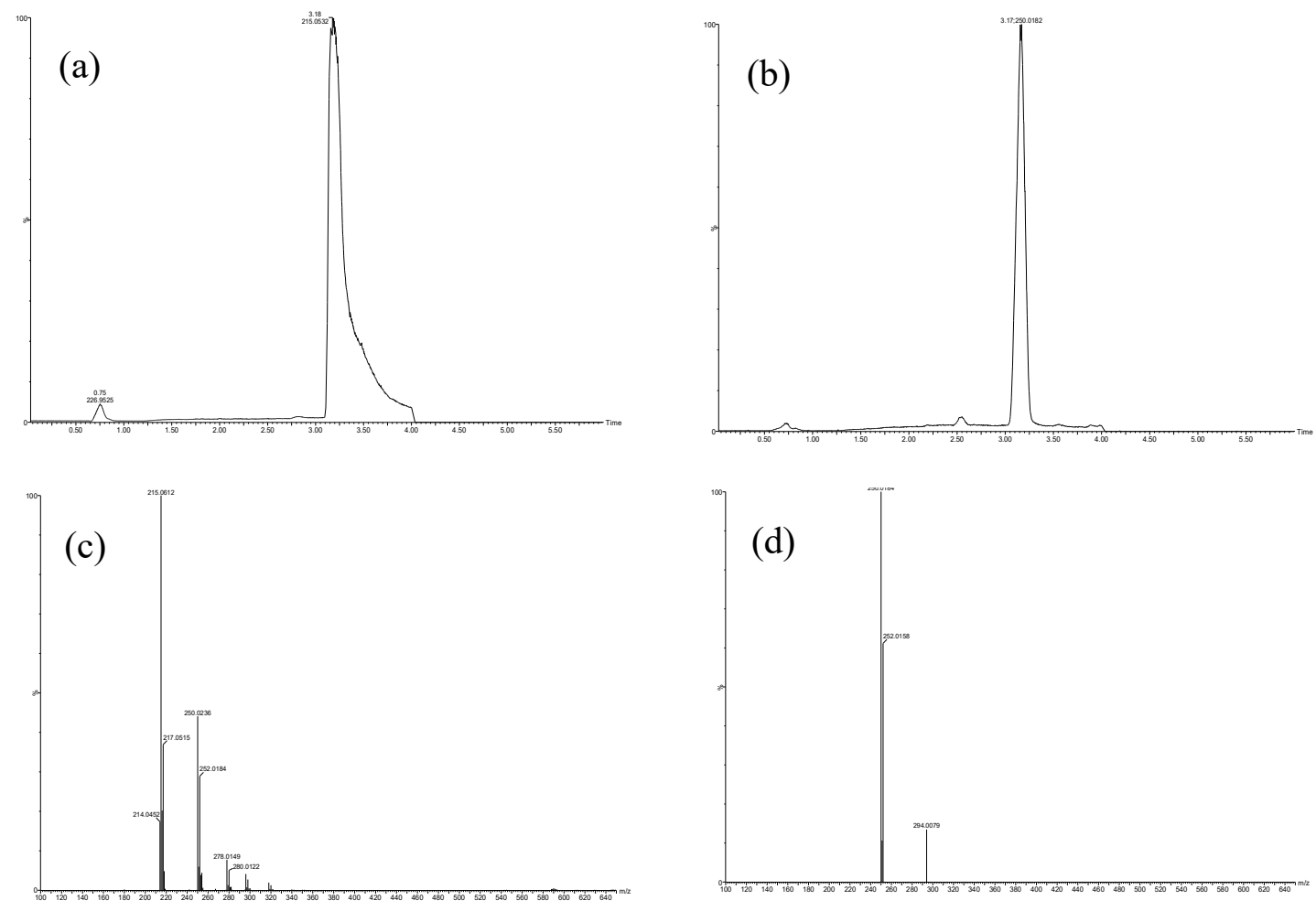

Figure 3. High-performance liquid chromatography (HPLC)- mass spectroscopy (MS) chromatographic patterns of DIC standard. (a) Total ion chromatogram (TIC) in the ESI+ mode, (b) TIC in the ESImode, (c) MS patterns in the ESI+ mode, and (d) MS patterns in the ESI- mode. 

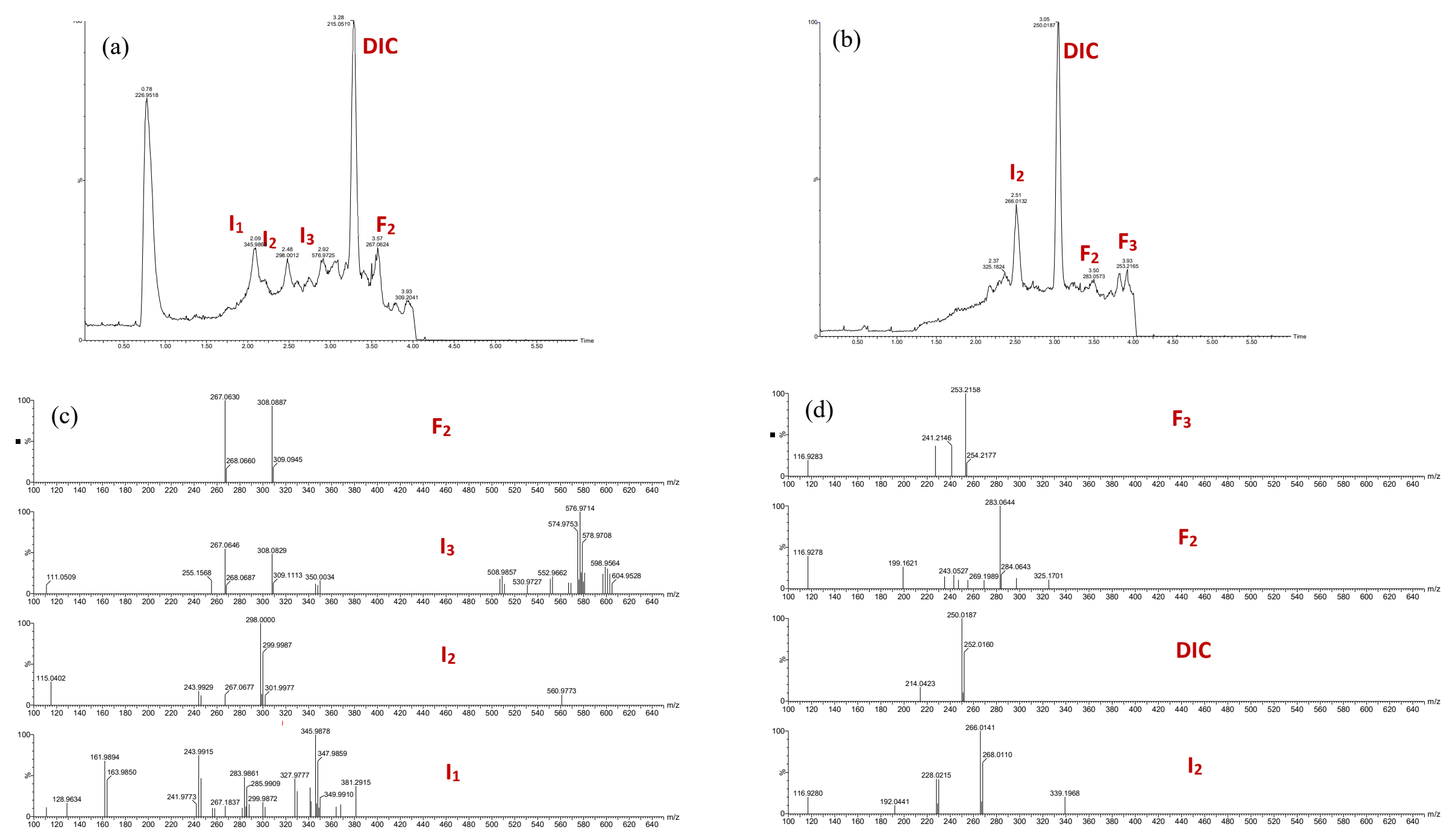

Figure 4. HPLC-MS chromatographic patterns of degradation intermediates. (a) TIC in the ESI+ mode, (b) TIC in the ESI- mode, (c) MS patterns in the ESI+ mode, and (d) MS patterns in the ESI- mode under a $\mathrm{pH}$ of 5 for a reaction time of $2 \mathrm{~h}$ with an initial $\mathrm{MnO}_{2}$ loading of $200 \mathrm{mg} / \mathrm{L}$. 

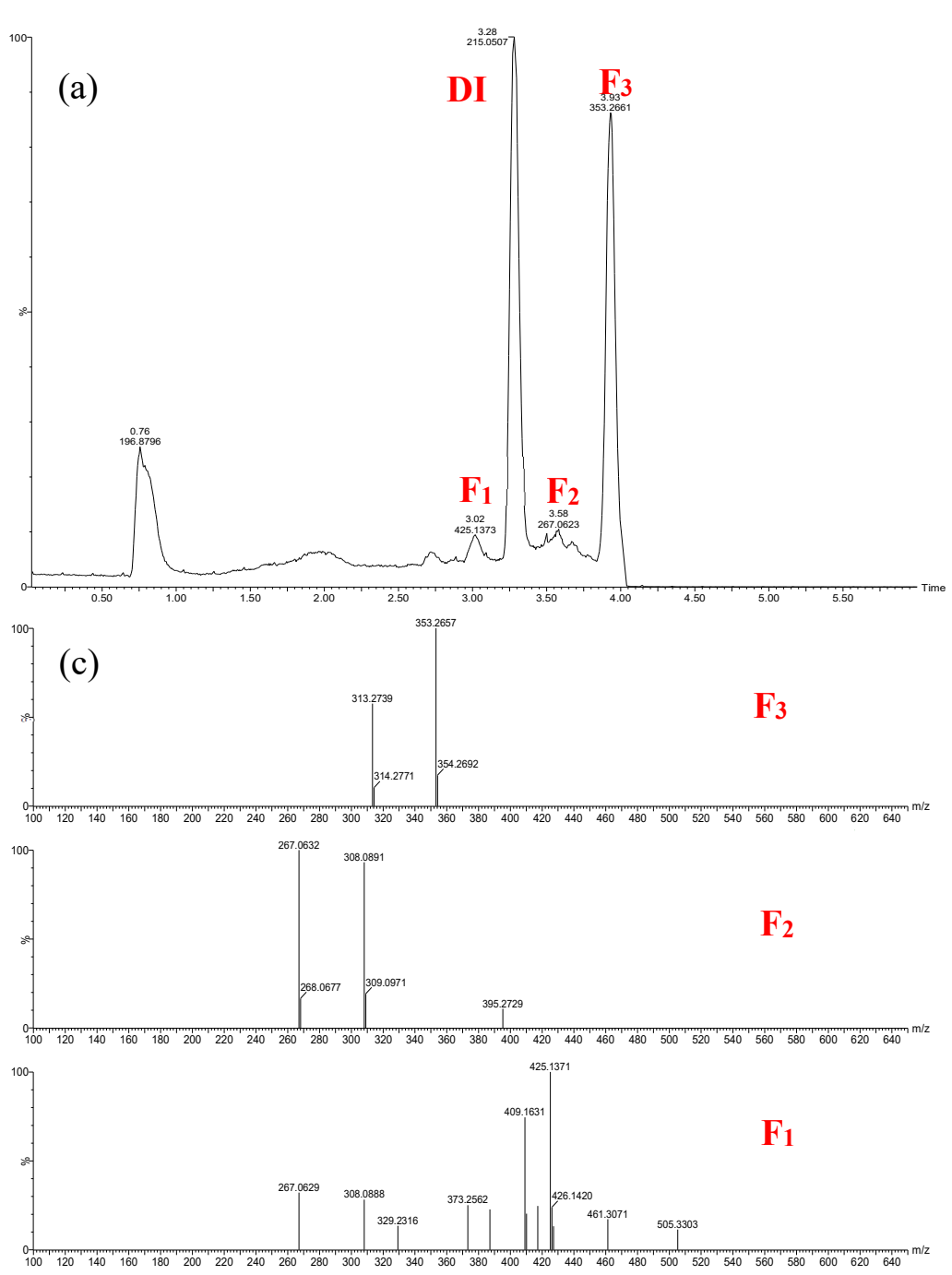
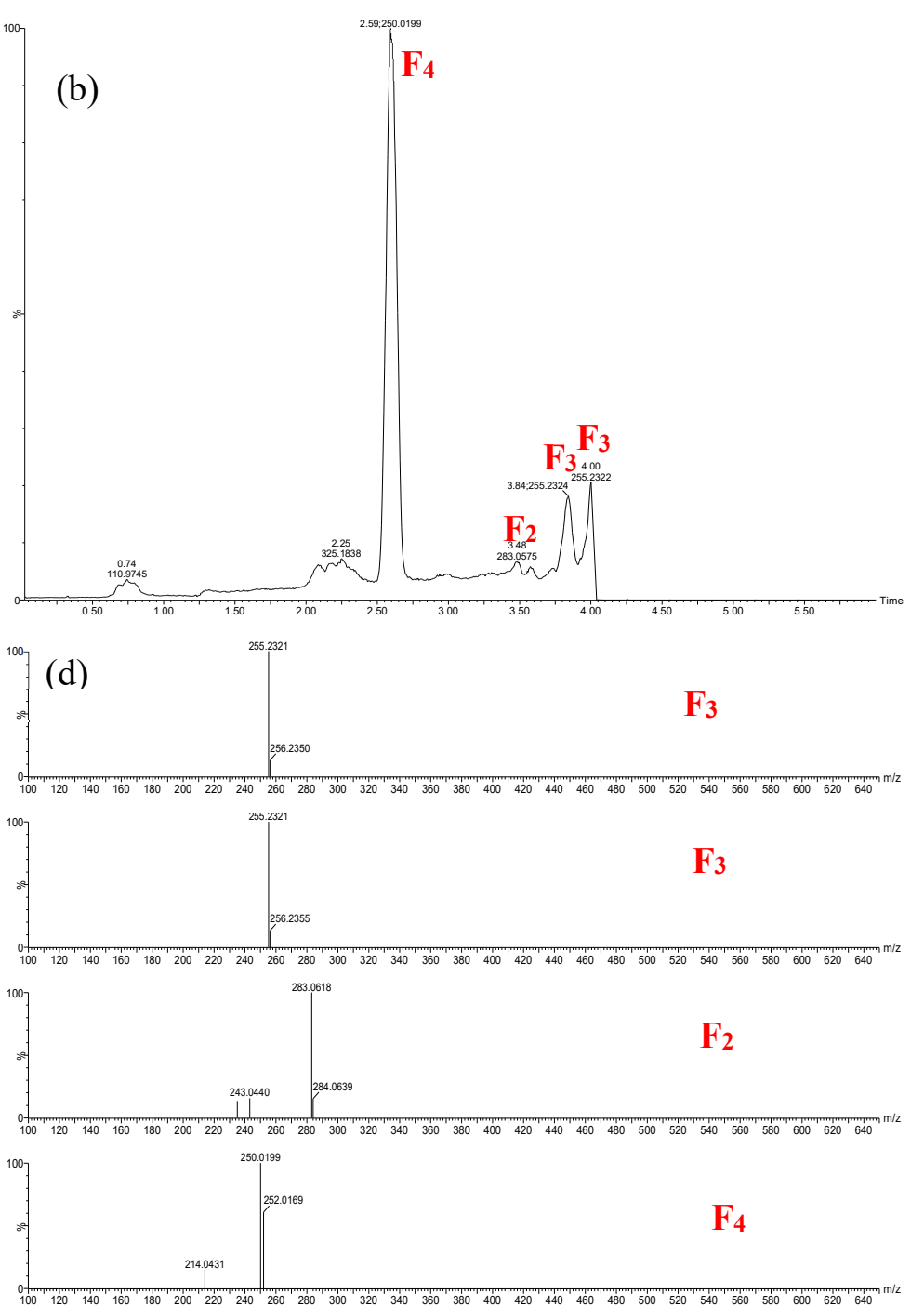

Figure 5. HPLC-MS chromatographic patterns of degradation products. (a) TIC in the ESI+ mode, (b) TIC in the ESI- mode, (c) MS patterns in the ESI+ mode, and (d) MS patterns in the ESI- mode under a $\mathrm{pH}$ of 5 for a reaction time of $24 \mathrm{~h}$ with an initial $\mathrm{MnO}_{2}$ loading of $200 \mathrm{mg} / \mathrm{L}$. 
According to Monteagudo et al. [52,53], $\mathrm{I}_{1}(\mathrm{RT}=2.09, \mathrm{~m} / \mathrm{z}=346)$ correspond totri-hydroxyl-DIC $(\mathrm{m} / \mathrm{z}=346)$ or di-hydroxyl-DIC $(\mathrm{m} / \mathrm{z}=328)$. I2 $(\mathrm{RT}=2.48, \mathrm{~m} / \mathrm{z}=298)$ should be a hydrolyzeddecarboxylated DIC $(296-14+16=298)$. The molecular weight of $I_{3}(R T=2.92, \mathrm{~m} / \mathrm{z}=597)$ is considerably higher than that of DIC. Moreover, $\mathrm{I}_{3}$ exhibited numerous isotopic peaks, and its intensity ratio of $(M+1) / Z$ to $(M+3) / Z$ was approximately 3:4, which revealed that these compounds contained four chlorine atoms. Thus, $\mathrm{I}_{3}$ should be a dimmer of 5 -iminoquinone DIC $(\mathrm{m} / \mathrm{z}=308)$ and another intermediate. This finding indicated that polymerization or dimerization, which was found during the reaction of other aromatic compounds with Mn-oxides, may occur during DIC degradation by $\gamma-\mathrm{MnO}_{2}$. Similar results were reported by Huguet et al. [26].

$\mathrm{F} 1(\mathrm{RT}=3.02, \mathrm{~m} / \mathrm{z}=503)$ is a new product, and its molecular weight is substantially higher than that of DIC. Therefore, it should be a transformation product of $I_{3} . F_{2}(R T=3.58, \mathrm{~m} / \mathrm{z}=308)$ and $\mathrm{F}_{3}(\mathrm{RT}=3.93, \mathrm{~m} / \mathrm{z}=312)$ correspond to 5-iminoquinone DIC and hydroxyl-DIC, respectively, which have been reported in literature [26]. The peak of hydroxyl-DIC $\left(\mathrm{F}_{3}\right)$ split into two and the $\mathrm{m} / \mathrm{z}$ ratio (255) in negative mode was considerably lower than the $\mathrm{m} / \mathrm{z}$ ratio (312) in the positive mode. The split of the peak could be attributed to the different sites of the hydroxyl group of the compound (structure isomers) leading to different hydrophilicity, and the observed difference of $\mathrm{m} / \mathrm{z}$ ratio for $\mathrm{F}_{3}$ between in positive mode and negative mode should result from the carbon chain $\left(-\mathrm{CH}_{2} \mathrm{COOH}\right.$, $\mathrm{M}=57)$ broke during ionization. $\mathrm{F}_{4}(\mathrm{RT}=2.59, \mathrm{~m} / \mathrm{z}=250)$ should be a decarboxylation product of DIC (2,6-dichloro-N-o-tolylbenzenamine), which was reported by Martínez et al. [54].

The intensity of $\mathrm{F}_{3}$ was much higher than that of $\mathrm{F}_{2}$, and multiple hydroxyl intermediates $\left(\mathrm{I}_{1}\right)$ were found. According to studies, decarboxylation, hydroxylation, and dimerization are the three main pathways of DIC transformation by Mn-oxides [26]. The pathways of DIC transformation by $\gamma-\mathrm{MnO}_{2}$ are the same as those of birnessite or other natural manganese oxides [26], and compared with the layer-structured birnessite that is widely used in studies, hydroxylation of DIC by $\gamma-\mathrm{MnO}_{2}$ was more active than that through other pathways. This phenomenon could corroborate that the large amounts of highly flexible corner-shared $\mathrm{MnO}_{6}$ may provide abundant reactive hydroxyl groups and facilitate oxidation for target pollutant degradation [50,51]. Therefore, the dimerization products of DIC obtained through $\gamma-\mathrm{MnO}_{2}$ are highly hydrophilic and can be detected without extraction. Hydroxylation intermediates were not detected after 1 day because they were oxidized to smaller or hydrophilic compounds due to further hydroxylation.

Table 2. MS data of intermediate and final products.

\begin{tabular}{|c|c|c|c|c|c|}
\hline Compound & RT (min) & Model & $\mathrm{m} / \mathbf{z}$ & Possible Structure & Ref \\
\hline \multirow[t]{2}{*}{ DIC } & \multirow[t]{2}{*}{3.18} & ESI+ & $\begin{array}{c}296 / 298(3 / 2) \\
278 / 280,250 / 252 \\
215 / 217\end{array}$ & & \\
\hline & & ESI- & $250 / 252(3 / 2)$ & & \\
\hline I1 & 2.09 & ESI+ & $\begin{array}{c}346 / 348(3 / 2) \\
328 / 330,284 / 286,244 / 246 \\
162 / 164\end{array}$ & $\begin{array}{c}\text { Tri or Di-hydroxyl } \\
\text { DIC }\end{array}$ & {$[52,53]$} \\
\hline \multirow[t]{2}{*}{ I2 } & \multirow[t]{2}{*}{2.48} & ESI+ & $\begin{array}{c}298 / 300(3 / 2) \\
267,244\end{array}$ & & \\
\hline & & ESI- & $\begin{array}{c}266 / 264(3 / 2) \\
228 / 230\end{array}$ & & \\
\hline I3 & 2.92 & ESI+ & $\begin{array}{c}597 / 599(3 / 4) \\
575 / 577(3 / 4) \\
551 / 553(3 / 4) \\
507 / 509(3 / 4), 308 \\
267,255\end{array}$ & Dimer & \\
\hline
\end{tabular}


Table 2. Cont.

\begin{tabular}{|c|c|c|c|c|c|}
\hline Compound & RT (min) & Model & $\mathrm{m} / \mathrm{z}$ & Possible Structure & Ref \\
\hline $\mathrm{F} 1$ & 3.02 & ESI+ & $\begin{array}{c}503 \\
461,425,409,373 \\
329,308,267\end{array}$ & Dimer & \\
\hline F2 & 3.58 & $\begin{array}{l}\text { ESI+ } \\
\text { ESI- }\end{array}$ & $\begin{array}{c}308 \\
267 \\
283\end{array}$ & & {$[26,55]$} \\
\hline F3 & 3.93 & $\begin{array}{l}\text { ESI+ } \\
\text { ESI- }\end{array}$ & 255 & & {$[26,55]$} \\
\hline $\mathrm{F} 4$ & 2.59 & ESI- & $\begin{array}{c}250 / 252(3 / 2) \\
214\end{array}$ & & [54] \\
\hline
\end{tabular}

RT: retention time; bold number: parent ion.

\section{Conclusions}

This study demonstrated that the $\mathrm{pH}$ of media highly influences DIC oxidative degradation on the tunnel-structured Mn-oxide $\left(\gamma-\mathrm{MnO}_{2}\right)$. The reduction potential of Mn-oxide, the number of surface reactive sites (S), and electrostatic affinity between DIC and $\gamma-\mathrm{MnO}_{2}$ increase with a decrease in $\mathrm{pH}$ value. Consequently, the electron-transfer control mechanism model successfully described degradation evolution with time under acidic conditions $(\mathrm{pH}=4-6)$. While under neutral-to-alkaline conditions ( $\mathrm{pH}=7-9$ ), the precursor complex-formation control mechanism was highly fitting to the experimental data. At pH 7-9 the anionic species account for 100\% DIC in solution and hence confront with the competition of $\mathrm{OH}^{-}$ions for the complex formation on the $\gamma-\mathrm{MnO}_{2}$ surface. In contrast, the acid form of DIC with a substantial ratio under $\mathrm{pH} 4-6$ is favored for the surface complex formation with less competition. The results of the analysis of oxidative intermediates and products by using HPLC-MS revealed decarboxylation, hydroxylation, and dimerization as the three main pathways of DIC transformation by $\gamma-\mathrm{MnO}_{2}$. Although the oxidation products obtained by $\gamma-\mathrm{MnO}_{2}$ are similar to those obtained by other Mn-oxides, hydroxylation of DIC by $\gamma-\mathrm{MnO}_{2}$ is more active than other pathways because of an abundance of flexible corner-shared $\mathrm{MnO}_{6}$ for target pollutant degradation.

Supplementary Materials: The following are available online: http://www.mdpi.com/2073-4441/12/8/2203/s1, Figure S1: DIC species distribution versus solution. HA and $\mathrm{A}^{-}$represent the acid and ionized form of DIC, respectively. The black and gray line were calculated based on $\mathrm{pKa}=4.15$ of DIC [44]. When $\mathrm{pH}$ higher than 7 , the ionized species $\left(\mathrm{A}^{-}\right)$accounts for $100 \%$ of DIC in solution $\mathrm{pH}$. Figure S2: LC-MS chromatographic patterns of degradation intermediates (a) TIC in $\mathrm{ESI}^{+}$mode (b) MS patterns in $\mathrm{ESI}^{+}$mode under $\mathrm{pH} 7.0$ for reaction time $=24 \mathrm{~h}$ with initial $\mathrm{MnO}_{2}$ loading $200 \mathrm{mg}$.

Author Contributions: C.-Y.H. conceived and designed the experiments. Y.-J.L. performed the experiments. C.-Y.H. and W.-H.K. analyzed the data and wrote the paper. All authors have read and agreed to the published version of the manuscript.

Funding: This research received the funding from Ministry of Science and Technology of the Republic of China, Contract No. NSC 98-2221-E-038 -004, MOST 105-2221-E-131-001-MY3 and MOST 108-2221-E-131-024-MY3.

Conflicts of Interest: The authors declare no conflict of interest. 


\section{References}

1. Ternes, T.A.; Herrmann, N.; Bonerz, M.; Knacker, T.; Siegrist, H.; Joss, A. A rapid method to measure the solid-water distribution coefficient $(\mathrm{K}-\mathrm{d})$ for pharmaceuticals and musk fragrances in sewage sludge. Water Res. 2004, 38, 4075-4084. [CrossRef] [PubMed]

2. Joss, A.; Zabczynski, S.; Gobel, A.; Hoffmann, B.; Loffler, D.; McArdell, C.S.; Ternes, T.A.; Thomsen, A.; Siegrist, H. Biological degradation of pharmaceuticals in municipal wastewater treatment: Proposing a classification scheme. Water Res. 2006, 40, 1686-1696. [CrossRef] [PubMed]

3. Camacho-Munoz, D.; Martin, J.; Santos, J.L.; Aparicio, I.; Alonso, E. Occurrence, temporal evolution and risk assessment of pharmaceutically active compounds in Donana Park (Spain). J. Hazard. Mater. 2010, 183, 602-608. [CrossRef] [PubMed]

4. Comeau, F.; Surette, C.; Brun, G.L.; Losier, R. The occurrence of acidic drugs and caffeine in sewage effluents and receiving waters from three coastal watersheds in Atlantic Canada. Sci. Total Environ. 2008, 396, 132-146. [CrossRef] [PubMed]

5. Schwab, B.W.; Hayes, E.P.; Fiori, J.M.; Mastrocco, F.J.; Roden, N.M.; Cragin, D.; Meyerhoff, R.D.; D'Aco, V.J.; Anderson, P.D. Human pharmaceuticals in US surface waters: A human health risk assessment. Regul. Toxicol. Pharmacol. 2005, 42, 296-312. [CrossRef]

6. Sidlova, P.; Podlipna, R.; Vanek, T. Cytotoxic pharmaceuticals in the environment. Chem. Listy 2011, 105, 8-14.

7. Tauxe-Wuersch, A.; de Alencastro, L.F.; Grandjean, D.; Tarradellas, J. Occurrence of several acidic drugs in sewage treatment plants in Switzerland and risk assessment. Water Res. 2005, 39, 1761-1772. [CrossRef]

8. Weber, S.; Khan, S.; Hollender, J. Human risk assessment of organic contaminants in reclaimed wastewater used for irrigation. Desalination 2006, 187, 53-64. [CrossRef]

9. Lonappan, L.; Brar, S.K.; Das, R.K.; Verma, M.; Surampalli, R.Y. Diclofenac and its transformation products: Environmental occurrence and toxicity-A review. Environ. Int. 2016, 96, 127-138. [CrossRef]

10. Oaks, J.L.; Gilbert, M.; Virani, M.Z.; Watson, R.T.; Meteyer, C.U.; Rideout, B.A.; Shivaprasad, H.L.; Ahmed, S.; Iqbal Chaudhry, M.J.; Arshad, M.; et al. Diclofenac residues as the cause of vulture population decline in Pakistan. Nature 2004, 427, 630-633. [CrossRef]

11. Taggart, M.A.; Senacha, K.R.; Green, R.E.; Jhala, Y.V.; Raghavan, B.; Rahmani, A.R.; Cuthbert, R.; Pain, D.J.; Meharg, A.A. Diclofenac residues in carcasses of domestic ungulates available to vultures in India. Environ. Int. 2007, 33, 759-765. [CrossRef] [PubMed]

12. Schmitt-Jansen, M.; Bartels, P.; Adler, N.; Altenburger, R. Phytotoxicity assessment of diclofenac and its phototransformation products. Anal. Bioanal. Chem. 2007, 387, 1389-1396. [CrossRef] [PubMed]

13. Stülten, D.; Zühlke, S.; Lamshöft, M.; Spiteller, M. Occurrence of diclofenac and selected metabolites in sewage effluents. Sci. Total Environ. 2008, 405, 310-316. [CrossRef]

14. Stone, A.T. Reductive dissolution of manganese(III/Iv) oxides by substituted phenols. Environ. Sci. Technol. 1987, 21, 979-988. [CrossRef] [PubMed]

15. Zhang, H.C.; Huang, C.H. Oxidative transformation of triclosan and chlorophene by manganese oxides. Environ. Sci. Technol. 2003, 37, 2421-2430. [CrossRef] [PubMed]

16. Park, J.W.; Dec, J.; Kim, J.E.; Bollag, J.M. Effect of humic constituents on the transformation of chlorinated phenols and anilines in the presence of oxidoreductive enzymes or birnessite. Environ. Sci. Technol. 1999, 33, 2028-2034. [CrossRef]

17. Ulrich, H.J.; Stone, A.T. The oxidation of chlorophenols adsorbed to manganese oxide surfaces. Environ. Sci. Technol. 1989, 23, 421-428. [CrossRef]

18. Li, H.; Lee, L.S.; Jafvert, C.T.; Graveel, J.G. Effect of substitution on irreversible binding and transformation of aromatic amines with soils in aqueous systems. Environ. Sci. Technol. 2000, 34, 3674-3680. [CrossRef]

19. Pizzigallo, M.D.R.; Ruggiero, P.; Crecchio, C.; Mascolo, G. Oxidation of chloroanilines at metal oxide surfaces. J. Agric. Food Chem. 1998, 46, 2049-2054. [CrossRef]

20. Lin, K.; Liu, W.; Gan, J. Oxidative removal of bisphenol A by manganese dioxide: Efficacy, products, and pathways. Environ. Sci. Technol. 2009, 43, 3860-3864. [CrossRef]

21. Lu, Z.J.; Lin, K.D.; Gan, J. Oxidation of bisphenol F (BPF) by manganese dioxide. Environ. Pollut. 2011, 159, 2546-2551. [CrossRef] [PubMed] 
22. Sarmah, P.; Dutta, D.K. Manganese mediated aqueous reduction of aromatic nitro compounds to amines. J. Chem. Res. 2003, 236-237. [CrossRef]

23. Rubert, K.F.; Pedersen, J.A. Kinetics of oxytetracycline reaction with a hydrous manganese oxide. Environ. Sci. Technol. 2006, 40, 7216-7221. [CrossRef] [PubMed]

24. Sabirova, J.S.; Cloetens, L.F.F.; Vanhaecke, L.; Forrez, I.; Verstraete, W.; Boon, N. Manganese-oxidizing bacteria mediate the degradation of $17 \alpha$-ethinylestradiol. Microb. Biotechnol. 2008, 1, 507-512. [CrossRef] [PubMed]

25. Xu, L.; Xu, C.; Zhao, M.; Qiu, Y.; Sheng, G.D. Oxidative removal of aqueous steroid estrogens by manganese oxides. Water Res. 2008, 42, 5038-5044. [CrossRef]

26. Huguet, M.; Deborde, M.; Papot, S.; Gallard, H. Oxidative decarboxylation of diclofenac by manganese oxide bed filter. Water Res. 2013, 47, 5400-5408. [CrossRef]

27. Forrez, I.; Carballa, M.; Verbeken, K.; Vanhaecke, L.; Schlusener, M.; Ternes, T.; Boon, N.; Verstraete, W. Diclofenac Oxidation by Biogenic Manganese Oxides. Environ. Sci. Technol. 2010, 44, 3449-3454. [CrossRef]

28. Nihemaiti, M.; Le Roux, J.; Hoppe-Jones, C.; Reckhow, D.A.; Croué, J.-P. Formation of haloacetonitriles, haloacetamides, and nitrogenous heterocyclic byproducts by chloramination of phenolic compounds. Environ. Sci. Technol. 2017, 51, 655-663. [CrossRef]

29. Chen, T.; Dou, H.; Li, X.; Tang, X.; Li, J.; Hao, J. Tunnel structure effect of manganese oxides in complete oxidation of formaldehyde. Microporous Mesoporous Mater. 2009, 122, 270-274. [CrossRef]

30. Luo, J.; Zhang, Q.; Garcia-Martinez, J.; Suib, S.L. Adsorptive and acidic properties, reversible lattice oxygen evolution, and catalytic mechanism of cryptomelane-type manganese oxides as oxidation catalysts. J. Am. Chem. Soc. 2008, 130, 3198-3207. [CrossRef]

31. Wu, C.; Xie, W.; Zhang, M.; Bai, L.; Yang, J.; Xie, Y. Environmentally friendly $\gamma$-MnO2 hexagon-based nanoarchitectures: Structural understanding and their energy-saving applications. Chem. A Eur. J. 2009, 15, 492-500. [CrossRef] [PubMed]

32. Zhang, J.; Li, Y.; Wang, L.; Zhang, C.; He, H. Catalytic oxidation of formaldehyde over manganese oxides with different crystal structures. Catal. Sci. Technol. 2015, 5, 2305-2313. [CrossRef]

33. Silberberg, M. Chemistry: The Molecular Nature of Matter and Change with Advanced Topics; McGraw-Hill: New York, NY, USA, 2018.

34. Stumm, W. Chemistry of the Solid-Water Interface: Processes at the Mineral-Water and Particle-Water Interface in Natural Systems; John Wiley \& Son Inc.: New Jersey, NJ, USA, 1992.

35. Samuelsson, J.; Forssén, P.; Fornstedt, T. Sample conditions to avoid pH distortion in RP-LC. J. Sep. Sci. 2013, 36, 3769-3775. [CrossRef] [PubMed]

36. Fornstedt, T.; Forssén, P.; Westerlund, D. System peaks and their impact in liquid chromatography. TrAC Trends Anal. Chem. 2016, 81, 42-50. [CrossRef]

37. Xyla, A.G.; Sulzberger, B.; Luther III, G.W.; Hering, J.G.; van Cappellen, P.; Stumm, W. Reductive dissolution of manganese (III, IV)(hydr) oxides by oxalate: The effect of $\mathrm{pH}$ and light. Langmuir 1992, 8, 95-103. [CrossRef]

38. De Oliveira, T.; Guégan, R.; Thiebault, T.; Le Milbeau, C.; Muller, F.; Teixeira, V.; Giovanela, M.; Boussafir, M. Adsorption of diclofenac onto organoclays: Effects of surfactant and environmental ( $\mathrm{pH}$ and temperature) conditions. J. Hazard. Mater. 2017, 323, 558-566. [CrossRef]

39. Das, R.N.; Roy, K. QSPR with extended topochemical atom (ETA) indices. 4. Modeling aqueous solubility of drug like molecules and agrochemicals following OECD guidelines. Struct. Chem. 2013, 24, 303-331. [CrossRef]

40. Loos, R. Analytical Methods for Possible WFD 1st Watch List Substances; European Commission, Joint Research Center, Onstitute fro Environment and Sustainability, Publications Office of the European Union: Luxembourg, 2015.

41. Zhao, J.; Wang, Q.; Fu, Y.; Peng, B.; Zhou, G. Kinetics and mechanism of diclofenac removal using ferrate (VI): Roles of $\mathrm{Fe}^{3+}, \mathrm{Fe}^{2+}$, and $\mathrm{Mn}^{2+}$. Environ. Sci. Pollut. Res. 2018, 25, 22998-23008. [CrossRef]

42. Zhang, H.C.; Chen, W.R.; Huang, C.H. Kinetic modeling of oxidation of antibacterial agents by manganese oxide. Environ. Sci. Technol. 2008, 42, 5548-5554. [CrossRef]

43. Zhang, H.C.; Huang, C.H. Oxidative transformation of fluoroquinolone antibacterial agents and structurally related amines by manganese oxide. Environ. Sci. Technol. 2005, 39, 4474-4483. [CrossRef]

44. Bui, T.X.; Choi, H. Influence of ionic strength, anions, cations, and natural organic matter on the adsorption of pharmaceuticals to silica. Chemosphere 2010, 80, 681-686. [CrossRef] [PubMed] 
45. Li, J.; Zhang, T.; Ye, M. Heterogeneous oxidation of diclofenac in the presence of $\alpha$-MnO2 nanorods: Influence of operating factors and mechanism. Water Sci. Technol. 2015, 71, 1340-1346. [CrossRef] [PubMed]

46. Liu, W.; Sutton, N.B.; Rijnaarts, H.H.; Langenhoff, A.A.J.E.S.; Research, P. Anoxic conditions are beneficial for abiotic diclofenac removal from water with manganese oxide $\left(\mathrm{MnO}_{2}\right)$. Environ. Sci. Pollut. Res. Int. 2018, 25, 10141-10147. [CrossRef] [PubMed]

47. Su, D.; Ahn, H.-J.; Wang, G. Hydrothermal synthesis of $\alpha-\mathrm{MnO} 2$ and $\beta-\mathrm{MnO}_{2}$ nanorods as high capacity cathode materials for sodium ion batteries. J. Mater. Chem. A 2013, 1, 4845-4850. [CrossRef]

48. Wang, Y.; Feng, X.; Villalobos, M.; Tan, W.; Liu, F. Sorption behavior of heavy metals on birnessite: Relationship with its Mn average oxidation state and implications for types of sorption sites. Chem. Geol. 2012, 292, $25-34$. [CrossRef]

49. Smith, P.F.; Deibert, B.J.; Kaushik, S.; Gardner, G.; Hwang, S.; Wang, H.; Al-Sharab, J.F.; Garfunkel, E.; Fabris, L.; Li, J.; et al. Coordination Geometry and Oxidation State Requirements of Corner-Sharing MnO6 Octahedra for Water Oxidation Catalysis: An Investigation of Manganite ( $\gamma$-MnOOH). ACS Catal. 2016, 6, 2089-2099. [CrossRef]

50. Li, G.; Li, K.; Liu, A.; Yang, P.; Du, Y.; Zhu, M. 3D flower-like $\beta-\mathrm{MnO}_{2} /$ reduced graphene oxide nanocomposites for catalytic ozonation of dichloroacetic acid. Sci. Rep. 2017, 7, 43643. [CrossRef]

51. Kasprzyk-Hordern, B.; Ziółek, M.; Nawrocki, J. Catalytic ozonation and methods of enhancing molecular ozone reactions in water treatment. Appl. Catal. B Environ. 2003, 46, 639-669. [CrossRef]

52. Monteagudo, J.M.; El-taliawy, H.; Durán, A.; Caro, G.; Bester, K. Sono-activated persulfate oxidation of diclofenac: Degradation, kinetics, pathway and contribution of the different radicals involved. J. Hazard. Mater. 2018, 357, 457-465. [CrossRef]

53. Yu, H.; Nie, E.; Xu, J.; Yan, S.; Cooper, W.J.; Song, W. Degradation of diclofenac by advanced oxidation and reduction processes: Kinetic studies, degradation pathways and toxicity assessments. Water Res. 2013, 47, 1909-1918. [CrossRef]

54. Martínez, C.; Canle, L.M.; Fernández, M.I.; Santaballa, J.A.; Faria, J. Aqueous degradation of diclofenac by heterogeneous photocatalysis using nanostructured materials. Appl. Catal. B Environ. 2011, 107, 110-118. [CrossRef]

55. Soufan, M.; Deborde, M.; Legube, B. Aqueous chlorination of diclofenac: Kinetic study and transformation products identification. Water Res. 2012, 46, 3377-3386. [CrossRef] [PubMed] 